IZA DP No. 6101

Work to Live or Live to Work?

Unemployment, Happiness, and Culture

Annabelle Krause

November 2011 


\title{
Work to Live or Live to Work? Unemployment, Happiness, and Culture
}

\author{
Annabelle Krause
}

$I Z A$

\section{Discussion Paper No. 6101 \\ November 2011}

\author{
IZA \\ P.O. Box 7240 \\ 53072 Bonn \\ Germany \\ Phone: +49-228-3894-0 \\ Fax: +49-228-3894-180 \\ E-mail: iza@iza.org
}

Any opinions expressed here are those of the author(s) and not those of IZA. Research published in this series may include views on policy, but the institute itself takes no institutional policy positions.

The Institute for the Study of Labor (IZA) in Bonn is a local and virtual international research center and a place of communication between science, politics and business. IZA is an independent nonprofit organization supported by Deutsche Post Foundation. The center is associated with the University of Bonn and offers a stimulating research environment through its international network, workshops and conferences, data service, project support, research visits and doctoral program. IZA engages in (i) original and internationally competitive research in all fields of labor economics, (ii) development of policy concepts, and (iii) dissemination of research results and concepts to the interested public.

IZA Discussion Papers often represent preliminary work and are circulated to encourage discussion. Citation of such a paper should account for its provisional character. A revised version may be available directly from the author. 


\section{ABSTRACT \\ Work to Live or Live to Work? Unemployment, Happiness, and Culture*}

Happiness drops when individuals become unemployed. The negative impact of the unemployment shock, however, may differ by cultural background. To test the hypothesis of a 'Teutonic work ethic', this paper takes advantage of Switzerland in its cultural diversity. By comparing different cultural groups in the same institutional setting, I empirically test whether such deep psychological traits have an influence on how unemployment is perceived. It is found that unemployment has a significantly negative effect on life satisfaction in Switzerland. I furthermore present evidence which confirms to some extent the hypothesis that Swiss German individuals suffer more from unemployment, although for the most part, these results are without statistical significance. Swiss Germans are additionally found to be happier than their French-speaking compatriots - independent of whether they are unemployed. This difference between Romanic and Germanic cultural backgrounds is in line with previous findings, but deserves further research attention.

JEL Classification: J28, J60, Z1

Keywords: life satisfaction, unemployment, cultural differences, Switzerland

Corresponding author:

Annabelle Krause

IZA

P.O. Box 7240

53072 Bonn

Germany

E-mail: krause@iza.org

\footnotetext{
"I would like to thank Beatrix Brügger, Anne Gielen, Rafael Lalive, Andrew Oswald, Ulf Rinne, Simone Schüller, participants at the Workshop on Redistribution and Well-Being 2011 in Lausanne and the EALE 2011 in Cyprus for helpful discussions and comments and Ulrike Steins for excellent research assistance. This paper is a substantially revised version of my master thesis handed in at the University of Lausanne in 2009 and has been realized using the data collected by the Swiss Household Panel (SHP), which is based at the Swiss Centre of Expertise in the Social Sciences FORS. The SHP project is financed by the Swiss National Science Foundation. All remaining errors are mine.
} 


\section{Introduction}

Various economists emphasize the importance of the insights related to well-being and its influence on (economic) policy decisions (Diener and Seligman, 2004; Frey and Stutzer, 2002a; Oswald, 2006). They argue that well-being is not only a personal goal, but that also society benefits from happier citizens. ${ }^{1}$ Although the detection of the true causal effect still remains an issue for some conclusions, happier people seem to be more productive and cooperative at work as well as more sociable and healthy (Oswald et al., 2009; Veenhoven, 2008). The effect of unemployment on life satisfaction has been of particular interest in the literature. Empirical evidence for various countries shows that individuals suffer from the unemployment shock - the standard empirical finding is a robust negative effect (e.g., Winkelmann and Winkelmann, 1998; Kassenboehmer and Haisken-DeNew, 2009; Clark et al., 2001; Blanchflower and Oswald, 2004). This supports the view that unemployment is an involuntary state - individuals suffer psychologically as well as socially (besides the obvious drop in income). The costs refer to the loss of a meaningful task in life and of personal relationships. Furthermore, a person's work and his or her status in life are often strongly associated, so that a form of social stigmatization arises when becoming unemployed. However, according to new classical macroeconomists, individuals choose to be unemployed voluntarily because they prefer getting unemployment benefits and additional leisure time to a dissatisfying wage and the time spent working. Contrary to the empirical evidence, a certain form of voluntary unemployment can probably not be neglected. There are certainly individuals who prefer to enjoy the benefits of the unemployment insurance or who are officially unemployed, but work in the shadow economy in order to avoid tax payments (Frey and Stutzer, 2002a). ${ }^{2}$

The aim of this paper is to investigate the effect of unemployment on subjective wellbeing against the background of cultural differences. ${ }^{3}$ Diener and Suh (1999) point out that culture has an influence on how people value life satisfaction and that citizens from different cultures grow up with different norms indicating what kind of emotions are desirable. Triandis (2000) examines the relationship between culture and subjective well-being and constitutes certain societal characteristics, such as tolerance, individualism, and cultural complexity to influence subjective well-being. These differential values can also play a role when becoming unemployed and the cultural aspect can therefore contribute new insights to the involuntary vs. voluntary unemployment debate. The intensity of the pain of unemployment might be experienced differently depending on the culture and deep psychological

\footnotetext{
${ }^{1}$ The terms happiness, life satisfaction and subjective well-being will be used interchangeably throughout this paper, even though one could argue that they are not exactly the same. However, for the purpose of this paper the differences are rather negligible. See Diener (2005) for definitions concerning these kinds of measures.

${ }^{2}$ A relatively new study using time use data finds that while unemployed feel less happy while performing an activity, they compensate this decrease in well-being by the time the employed do not have and therefore, average experienced utility does not differ (Knabe et al., 2010). This finding challenges the standard finding of a negative effect of unemployment.

${ }^{3}$ For general economics of culture literature, see for instance, Guiso et al. (2006) and Tabellini (2010).
} 
attitudes one grew up with. In this context, I mainly refer to attitudes towards work which one actually inherited through culture and which are therefore assumed to be exogenous and not fundamentally changing over time or through certain life events. Thus, the hypothesis of this analysis is that individuals from cultures with a stronger work ethic and for whom working itself has additional value besides the purpose of earning one's livelihood are affected more negatively by unemployment than individuals from other cultures. This analysis therefore differs from studies which investigate social norm effects in the unemploymenthappiness relationship (Stutzer and Lalive, 2004; Clark, 2003; Clark et al., 2009), since it is not based on a social comparison hypothesis, but rather on intrinsic motivation. Certain people feel worse when they are unemployed not (only) because they experience social pressure, but because they themselves perceive working as more important than individuals from a different culture.

The analysis is performed for Switzerland, which presents an interesting setting. The country is often referred to as a nation of will rather than a population of the same ethnic origin or common culture. It is divided into several language regions, namely Swiss German and languages which originated from Latin - French, Italian and Romansh ('Röstigraben' border). Therefore, I argue that these different language regions, in particular the Swiss German-speaking part vs. the other parts, present different cultures concerning several domains in life, including the attitude towards working and the exposure to unemployment (Mayer, 1951; Hofstede, 1984; McRae, 1998; Büchi, 2000). For instance, in a survey on work attitudes, it was found that a higher percentage of Swiss Germans would go to work even if they did not need the money than French or Italian Swiss (Diekmann et al., 1999; Brügger et al., 2009). Historical and geographical reasons might have influenced the development of different cultures. The pride of their independence and the harder living conditions in the Alp regions might have contributed for Swiss-Germans to be harder working and attaching a higher value to work than the rest of the country. Questions regarding social and economic policy decisions as well as foreign policies these days concerning, for instance, the European Union often reveal a divergence of opinions between the Swiss regions (Büchi, 2000). Furthermore, speaking different languages let individuals turn to sources of media which they understand. Therefore the different regions are also greatly influenced by culture which rather originates from their larger neighbor countries than their neighbors within the country as well as regional media sources. A paper which has addressed the argument of cultural differences within Switzerland is Brügger et al. (2009). They argue that the two cultures in the Swiss regions have an effect on tastes for leisure, which in turn have an influence on the unemployment duration. The assumption concerning the effect of unemployment is therefore first, that unemployment causes a drop in subjective well-being and second that Swiss Germans experience a stronger effect of unemployment, because they attach a higher value to their working life -'Teutonic work ethic'- than Swiss people in the non-German speaking regions. The inherent culture is approximated by language in this analysis, which seems like a reasonable proxy, since language is a main channel through which a collective pattern of attitudes, norms and values is transmitted (Dorn et al., 2008; Lazear, 1999). An 
advantage of performing the analysis within one country rather than comparing different countries is the same institutional background that individuals grew up and live in. One can rule out effects arising from different social systems and actually assume that (after controlling for socio-demographic and socio-economic characteristics) the only factor differing between groups is culture.

The empirical analysis is done with data from the Swiss Household Panel, where I use the waves from 2000-2010. The main results are that there is a clear negative effect of unemployment on life satisfaction in Switzerland. To some extent, I find evidence which confirms a 'Teutonic work ethic', however, for the most part without any statistical significant difference between Swiss German and Swiss French men. An additional interesting finding is that Swiss German individuals are happier on average than other Swiss - independent of whether they are unemployed. Furthermore, the results show that it is important to use panel data, when existing, since certain findings differ between estimation methods.

The remainder is structured as follows: the data and sample description and results from a descriptive analysis are given in Section 2, which are followed by the empirical results in Section 3. Section 4 concludes.

\section{Data}

This section provides information on the data source and the sample used in the analysis followed by a descriptive analysis of the main variables of interest and the control variables. The data used for analysis stem from the Swiss Household Panel (SHP), which was first conducted in 1999 and aims to observe social change in Switzerland. ${ }^{4}$ The panel is comparable to household panels from other countries such as the GSOEP in Germany and the BHPS in Great Britain. Starting out with a sample of 7,799 individuals for the personal interview and 5,074 households for the household interview, the SHP has suffered attrition problems as many long term data sets do. Therefore, in 2004 a recruitment of 2,538 new households and 3,654 new participants for the individual questionnaire took place. The representative survey is conducted annually.

\subsection{Sample}

The waves between 2000 and 2010 are used for analysis. Unfortunately, the outcome variable satisfaction with life in general was not conducted in 1999 yet, so that this year is not included in the sample. The question concerning life satisfaction in the personal interview is the following: "In general, how satisfied are you with your life if 0 means 'not at all satisfied' and 10 means 'completely satisfied'?", where the answers are given on a scale from 0 to

\footnotetext{
${ }^{4}$ For more information see www.swisspanel.ch.
} 
10. ${ }^{5}$ These subjective variables pose some potential biases in the analysis and are reasons for which research with subjective data is still criticized by some economists. Unobserved individual specific effects can have an influence on the given responses and the so-called omitted-variable bias may arise. If these unobserved traits are time-invariant, the use of panel data and inclusion of fixed effects help to overcome these problems (Frey and Stutzer, 2002b; Graham, 2008). Related to this is the problem that not all respondents might interpret the scale in the same way. However, Diener and Lucas (2000) argue that in the literature so far, self-reported life satisfaction has shown to be a valid and consistent measure of subjective well-being. For instance, self-reports and other variables such as interview ratings, peer reports and the average daily ratio of pleasant to unpleasant moods were found to show a strong convergence.

Table 1 shows the distribution of average life satisfaction by employment status and mother tongue of male respondents. ${ }^{6}$ One can see that Swiss Germans report the highest values of life satisfaction, about 8 on average, followed by Swiss Italians. Swiss French individuals are the least happy. There might be already a cultural difference arising at this point, since there is evidence that individuals having Romanic languages as mother tongue are less happy than individuals with a Germanic background (Dorn et al., 2007). In line with this, Senik (2011) examines the "unhappiness" of French people in a European-wide study. However, she does not find differences between Swiss German and Swiss French, but between Swiss German and Swiss Italian. Dorn et al. (2008) find Swiss Germans to be the happiest group in Switzerland. In order to shed some more light on these findings, in Table 2 the distribution of life satisfaction of German, French and Italian immigrants to Switzerland in the SHP data is plotted and the same picture arises. Germans indicate the highest life satisfaction on average, and French the least. This distribution actually persists when dividing the Swiss groups up into employed and unemployed respondents, see Table 1. When employed, Swiss Germans are again the happiest, followed by Swiss Italians and lastly French-speaking Swiss. Unemployed individuals are clearly less happy than employed. From these numbers, it seems that Swiss Italian respondents are the happiest unemployed. However, there are only two observations for unemployed Swiss Italians. Therefore, and since Swiss Italian respondents differ in too many respects from Swiss French, they will be excluded from the sample, since they are too small to comprise an own group of analysis. Apart from that, the hypothesis that Swiss Germans are less happy when unemployed cannot be confirmed with these numbers.

The final sample then excludes Italian-speaking respondents, women, non-Swiss nationals, individuals who are not in the labor force, and respondents who are not between 20 and 65 years old. Through this sample selection a clean effect of only Swiss respondents who are closely attached to the labor market, work mostly full-time and belong to the working age

\footnotetext{
${ }^{5}$ In the SHP, the interviews are conducted in German, French and Italian. The life satisfaction question is termed in the same way in all languages, so biases arising through different wording can be ruled out.

${ }^{6}$ There is no question on mother tongue in the SHP, so it is approximated by the first language the respondent relates to and masters best. However, they should be highly correlated.
} 
population can be detected. After dropping missing observations, I am left with a sample of 16,225 observations and 3,397 individuals for the whole time period.

\subsection{Descriptive Statistics}

Unfortunately, there is no information on attitudes towards work or comparable opinions in the SHP. In order to get some insight about somehow related differences between Swiss German and Swiss French individuals, in Table 3 the opinion on the Confederation social expenses is plotted. The question relates to whether the respondent is in favor of an increase or decrease of the federal social expenditures, which includes unemployment benefits. Higher numbers display being in favor of an increase, where the scale is set between 1 and 3 . This is of course rather a political than a cultural opinion, but can give some intuition as to how at least opinions between the two groups under analysis differ. Besides, one can assume that this political opinion is also reflecting certain cultural values. The numbers show that Swiss French men are more likely to be in favor of an increase of social spending than Swiss German men, no matter whether they are unemployed or not. These differences are always statistically different from zero. An interpretation is that Swiss Germans put a higher value on work itself and therefore also want this to be regarded in the social system so that one is not "rewarded" for becoming unemployed and getting even higher unemployment benefits. Importantly, the difference between groups persists when respondents are unemployed, which points to a deeper inner attitude towards this political issue than just an opinion built upon outside events.

Table 4 displays summary statistics of the whole sample and all control variables used in the regression analyses later on. ${ }^{7}$ About 75 percent of the sample belong to the Swiss German-speaking and about 25 percent to the French-speaking group. This distribution seems reasonable, since the Federal Statistical Office in Neuchâtel indicates that in 2000, 72.5 percent of the Swiss population had German as main language, 21 percent French, 4.3 percent Italian, and the rest Romansh or other languages. One can see that among Swiss French respondents, there is a higher share of unemployed, which is consistent with the general distribution of unemployment rates in Switzerland. They tend to be higher in nonGerman-speaking parts, which is why the average cantonal unemployment rate is included in the regression analysis to be able to rule out, e.g., social comparison effects. Information is gathered from the State Secretariat for Economic Affairs (SECO) and listed in the last row of Table 4. The unemployment rates are divided up according to German or French-speaking cantons and not the approximated mother tongue of the respondent. One can see that the unemployment rate in the French-speaking part is about 4 percent and therefore significantly higher than the one in the German-speaking part with 2.5 percent. $^{8}$

As seen in Table 1, Swiss Germans report higher values of life satisfaction than Swiss

\footnotetext{
${ }^{7}$ Except time and canton dummies which will be included in the regressions.

${ }^{8}$ For an explanation of the division of the language regions and other variables, see Table 12 . The bilingual cantons Berne, Fribourg and Valais are divided up according to what language the majority speaks.
} 
French individuals. This difference is always statistically significant, even when comparing the unemployed. Basically all other control variables also exhibit a statistically significant difference between language groups. Swiss German men are slightly older, almost 44 years on average and they are less likely to be married. The educational distribution is quite interesting, since there is a very low fraction of Swiss Germans who do not have any educational degree, whereas this percentage is zero for Swiss French individuals. Furthermore, Swiss Germans rather have low or intermediate educational degrees than high degrees compared to Swiss French. The average net yearly household income is higher for Swiss German households and amounts to $125,147.90$ Swiss Francs. ${ }^{9}$ These variables give a quite realistic demonstration of the Swiss population.

There is a debate about the causal direction of life satisfaction and unemployment. Are the people who become unemployed maybe the ones who were already less satisfied in the first place? Table 5 provides evidence against this argument. The numbers display the average change in life satisfaction from one period to the other according to employment status, where four different patterns may arise - becoming unemployed or reemployed, staying employed or staying unemployed. The strongest changes experience people who become unemployed, displayed in the first line. Both language groups experience a drop in their life satisfaction, where interestingly the drop for Swiss German men is almost twice as high as the one for Swiss French men. This provides evidence for the hypothesis that Swiss German men suffer more from unemployment, however, the difference is not statistically significant. Interestingly, this observation is only present when looking at the actual change in life satisfaction when this life event happened and not at the average distribution of the overall sample as seen before. In contrast, both groups experience an increase in life satisfaction when becoming reemployed. This increase is higher for Swiss Germans, which also gives evidence for their higher valuation of work and point to a closer labor market attachment. Individuals who stay employed over time do not indicate large changes in life satisfaction. The effect of staying unemployed goes into different directions for the two language groups. Swiss German men do not seem to cope with long-term unemployment, since their change in life satisfaction is negative. On the other hand, Swiss French experience an increase in happiness, which gives evidence for the hypothesis that unemployed people get used to their situation. These two differential effects would provide further evidence for the hypothesis under study, but since the number of observations for long-term unemployed is quite low, no reliable conclusions can be drawn. In addition, this difference is not statistically different from zero. These numbers give further evidence for the general argument that the causal effect goes from unemployment to dissatisfaction and not the other way around and provides some evidence for a 'Teutonic work ethic'.

\footnotetext{
${ }^{9}$ The Federal Statistical Office in Neuchâtel indicates the average monthly household net income in 2008 in Switzerland as 6,465 Swiss Francs, which gives a yearly income of 77,580 Swiss Francs. The sample seems to be composed of more respondents receiving a relatively high wage, which, however, should not seriously harm the analysis.
} 


\section{Results}

The baseline regressions are estimated by four different models. Since the dependent variable life satisfaction is a discrete variable with several outcomes, different methods are used to deal with that kind of variable in a panel data set. First, a standard OLS analysis is done, even if the problem of not having a continuous dependent variable is obvious. A pooled regression is estimated first and then a fixed effects analysis is done in order to remove unobserved individual effects. This allows observing how fixed effects change the coefficients.

Additionally, a conditional fixed effects ordered logit model is estimated based on the work of Chamberlain $(1980,1984)$ to take into account the ordinality of the dependent variable. The standard maximum likelihood estimator gives inconsistent results, so that a conditional version is used. For estimation of this model, the dependent variable has to be collapsed into a binary one, for which different methods exist. One can simply take the sample average and code respondents giving answers above the average 1 and the others 0. Furthermore, Ferrer-i-Carbonell and Frijters (2004) propose to use individual-specific thresholds to collapse life satisfaction into a binary variable. This approach has the advantage of not resulting into such a large data loss as using the sample average, since in this estimation method, only individuals who switch across the cut-off point are used. However, since Baetschmann et al. (2011) showed that the aforementioned methods lead to inconsistent estimators, the "Blow-Up and Cluster" (BUC) estimator proposed by them is used here. The idea is to replace every observation by $K-1$ copies of itself, where $K$ are the ordered outcomes of the dependent variable, dichotomize every copy of the individual at a different cut-off point and estimate a conditional maximum likelihood logit model.

The fourth method relies on the work of Boes and Winkelmann (2010). They develop a generalized ordered probit model with random effects for panel data. In contrast to the single-index ordered probit model, they formulate a multiple-index model, such as the multinomial logit model. Thus, the parameters are outcome or category-specific, so they can vary by the different outcome levels. The threshold values are not treated as constants but depend on regressors. A model of this kind allows seeing whether possible effects vary by the level of life satisfaction and where they are the strongest or weakest.

For follow-up regressions, only linear models are used which seem adequate for the sake of interpretation in this analysis. The main coefficients of interest are the dummies on unemployment, being Swiss German and an interaction term between the two. If the hypothesis on Swiss Germans perceiving unemployment as worse than Swiss French is to be confirmed, the interaction term is expected to be statistically significant from zero with a negative sign. If this was the case, while controlling for all other important determinants, the coefficient of the interaction term would be interpreted as a cultural effect. 


\subsection{Baseline Regression}

Tables 6 and 7 display the results for the stepwise baseline regression. Coefficients of interest are initially included, followed by controls for years, cantons and the unemployment rate. Eventually all socio-demographic and socio-economic characteristics are added. ${ }^{10}$ The BUCcoefficients do not display marginal effects, which cannot be computed at this stage, so that the interpretational comparison with the linear fixed effects coefficients will rely on the sign and significance level. The clear negative significant effect of unemployment on life satisfaction in Switzerland compared to the reference group employment is very persistent across estimation methods and specifications. Comparing the pooled with the fixed effects model, one can see that the coefficient reduces by half its size from -1.062 to -0.501 when one includes fixed effects in the first specification. Hence, half of the pooled effect is explained by unobserved individual characteristics. As already seen in the descriptive analysis, being Swiss German has a significantly positive effect on life satisfaction, which slightly decreases in magnitude and significance throughout specifications and due to the nature of fixed effects models, drops out in those estimations. When including the interaction term on unemployed and Swiss Germans, it appears positive in all pooled estimations, but then interestingly turns negative once fixed effects are included. Besides, the magnitude of the coefficient does not change when including other characteristics. This provides evidence for the main hypothesis, namely that Swiss Germans are hit harder when they become unemployed, however, neither in the linear nor in the non-linear model, the coefficient is significantly different from zero. Therefore, the hypothesis cannot be clearly confirmed.

Furthermore, it is important to control for cantonal unemployment rates, since the two regions are characterized by a persistent difference in this particular factor. The unemployment rate has a rather negative effect on life satisfaction, which practically vanishes in terms of magnitude and significance when controlling for socio-demographic and socio-economic characteristics. Age has a U-shaped effect since the linear coefficient is negative and the coefficient on the squared term is positive. This means that up to a certain age, individuals tend to indicate lower satisfaction levels, which then inverses after reaching the turning age. Being married has a positive effect, where the reference group is being single. However, this effect decreases largely in the fixed effects models. Being separated or divorced has a negative effect on life satisfaction. Interestingly, becoming a widow only shows up with a statistically significant coefficient in the fixed effects models, where also the sign turns negative. So the shock event seems to matter rather in the year when it actually happens. This coefficient and the one on the interaction term of unemployed Swiss Germans are the only ones which change signs between pooled and fixed effects models, which give evidence that

\footnotetext{
${ }^{10}$ It is common to control for individual health status in happiness analyses. Rather objective health measures such as chronic illnesses are only available since 2004 in the SHP, so that one is left with subjective health status as possible control variable. However, it seems somehow problematic to have subjective variables (where causation might run both ways) on both the left- and the right-hand side of the equation, so that I finally decided to leave health out of the estimation. As a robustness check, the estimations were run including subjective health. Results remained virtually the same.
} 
experiences work through distinct channels for those variables. The higher education levels show mostly a positive significant effect compared to the reference group low education degree. Income has a positive significant effect throughout estimation methods. Basically, all results are quite intuitive.

Table 8 displays the results for the generalized ordered probit model. ${ }^{11}$ The coefficients have to be interpreted in a slightly different way. As mentioned before, there are now different coefficients for different satisfaction levels. There are nine levels (by combining the lowest three answer possibilities 0,1 and 2 to one level) and each $\theta_{j}$ displays the coefficients for the dichotomized categories. In other words $\theta_{1}$ contrasts satisfaction level 1 with levels 2 to $9, \theta_{2}$ contrasts levels 1 and 2 with levels 3 to 9 and so on. Positive coefficients indicate a higher probability that the respondent will indicate a higher level of life satisfaction than the respective one. Negative coefficients therefore indicate a higher probability to indicate the respective level or a lower one. Such results help to understand at which points of the distribution of life satisfaction the effects might be stronger or do not play an important role.

Unemployment has again a highly significantly negative effect at almost all satisfaction levels, which is more prominent at the intermediate levels than at the very low or very high ones. Swiss Germans are more likely to indicate higher values on the 11-point scale at the upper part of the distribution between values 5 and 10. At one rather low level they are even less likely to indicate higher values. Almost all coefficients of the interaction term have a negative sign and the one on $\theta_{8}$ is significantly different from zero. For this highest satisfaction level, the effect of unemployment is actually significantly positive. It seems that at the top of the satisfaction distribution, the general effect of unemployment would not be significant. However, breaking it up between groups reveals that unemployed Swiss Germans are significantly more likely to indicate lower levels of life satisfaction at the top of the distribution compared to unemployed Swiss French men. These numbers provide some evidence confirming the hypothesis that Swiss Germans suffer more from unemployment.

\subsection{Follow-Up Analyses}

The baseline analysis has shown that there seem to be slight differences between the two cultural groups regarding the effect of unemployment on life satisfaction in Switzerland, but for the most part these were not found to be statistically different from zero. Three follow-up analyses are supposed to show whether a differential effect exists for certain subgroups.

The first idea is to only look at individuals who live in the French-speaking part of Switzerland. By doing this, one can find out whether the impact of unemployment is different for a person, who grew up in one region with that kind of cultural background, but now lives in the other region. Main results are displayed in Table 9. German speakers again have a significantly higher life satisfaction than the French speakers in the pooled regression,

\footnotetext{
${ }^{11}$ Only results of the main coefficients are presented here. Further results are available on request from the author.
} 
shown in the first column. Looking at the interaction term in this very same regression, it is negative and not positive as in the baseline regressions. Swiss Germans living in the French part therefore perceive unemployment on average worse than French speakers. This effect is confirmed in the fixed effects regression where the coefficient even becomes statistically significant from zero. However, it cannot be completely attributed to cultural reasons, since it could also be related to the fact that becoming unemployed and at the same time living in a region where people do not speak the mother tongue causes a larger drop in life satisfaction. A general higher dissatisfaction cannot be the reason since it was shown that German speaking individuals living in the French part also indicate higher satisfaction levels.

Switzerland does not only represent an interesting research setting through its several language regions, but there are also three bilingual cantons, where both German and French are official languages. This gives a further opportunity to isolate the pure cultural effect by comparing individuals only within these cantons. The results are displayed in Table 10. The first observation is that within bilingual cantons, Swiss Germans do not indicate significantly higher levels of life satisfaction. The Swiss German dummy is positive, but not statistically significant. In both, the pooled and the fixed effects regression, the interaction effect is negative and even larger than in the baseline regressions. However, it is again not statistically significantly different from zero. Interestingly, unemployment does not have a statistically significant effect on life satisfaction in these regressions. Further analyses with stepwise regressions show that without the interaction term, unemployment has a significantly negative effect. ${ }^{12}$ This indicates that mostly Swiss Germans perceive unemployment as a negative shock in the bilingual cantons, which provides evidence for the paper's hypothesis.

Another possible differential perception of unemployment is when it comes to being unemployed for a longer period or when one has been unemployed before. Table 11 displays results for regressions when controlling for past unemployment experiences. In the pooled case, evidence against the hypothesis of adaptation to life situations is provided, since the coefficient on past unemployment is significantly negative. However, its magnitude and significance vanishes when controlling for fixed effects. The interaction term with Swiss Germans is neither in the pooled or fixed effects case significantly different from zero. The magnitude is also very low, so it seems that past unemployment is not perceived differently by the two language groups and in general does not seem to have a statistically significant effect on life satisfaction once individual heterogeneity is taken into account.

\section{Conclusion}

This paper contributes to the literature on the effect of unemployment on life satisfaction by taking into account a possible cultural influence in this relationship. This collective pattern of beliefs, norms, and role definitions contains attitudes towards work, which in turn influence how unemployment is perceived. Switzerland presents an ideal setting for the analysis,

\footnotetext{
${ }^{12}$ Step-wise regression results from this analysis are not shown, but available on request from the author.
} 
which provides the clear advantage of being able to compare different cultural groups against the same institutional background. In particular, Swiss German-speaking men are compared with French-speaking men. Swiss Germans are assumed to have a stronger attitude towards work and valuate employment more highly. I test this hypothesis of a 'Teutonic work ethic' with data from the Swiss Household Panel. The years 2000-2010 are used to provide a thorough empirical analysis and the estimations are performed with several models in order to properly treat an ordered dependent variable in a panel data setting.

The negative effect of unemployment on subjective well-being, which has been found in numerous other studies, is also very apparent in Switzerland. There seems to be a differential impact on the two groups under analysis. When including fixed effects into the model, becoming unemployed and having a Swiss German background has a negative impact on life satisfaction. However, this difference is not statistically significant. A generalized ordered probit model reveals that in particular at the top of the life satisfaction scale, unemployed Swiss Germans are more likely to indicate lower values than Swiss French. Furthermore, unemployed Swiss Germans who live in the French-speaking region are found to be significantly less happy than their unemployed French compatriots and Swiss Germans seem to drive the negative effect of unemployment in bilingual cantons. Therefore, some evidence for the hypothesis that Swiss German men suffer more from unemployment is found, but mostly due to a lack of statistical significance it cannot be confirmed with certainty.

Another important finding is that Swiss Germans tend to indicate higher values of life satisfaction - independent of whether they are unemployed. This difference in happiness between individuals from Romanic and Germanic cultures was found before (Dorn et al., 2007, 2008; Senik, 2011). An interesting question for further research is therefore how this difference evolves. Is there actually a cultural divide in happiness and how individuals with these backgrounds valuate their life? Or does only the interpretation of the satisfaction scale differ between groups, which would then lead to incorrect conclusions? Research aiming at the individual's actual evaluation of the scale could shed more light on this important issue, where anchoring vignettes present one possibility to address this (King et al., 2004). 


\section{References}

Baetschmann, G., K. E. Staub, and R. Winkelmann (2011). Consistent Estimation of the Fixed Effects Ordered Logit Model. IZA Discussion Paper 5443, Institute for the Study of Labor (IZA), Bonn.

Büchi, C. (2000). Röstigraben. Das Verhältnis zwischen deutscher und französischer Schweiz. Geschichte und Perspektiven. Verlag Neue Zürcher Zeitung.

Blanchflower, D. and A. Oswald (2004). Well-Being over Time in Britain and the USA. Journal of Public Economics 88, 1359-1386.

Boes, S. and R. Winkelmann (2010). The Effect of Income on General Life Satisfaction and Dissatisfaction. Social Indicators Research 95(1), 111-128.

Brügger, B., R. Lalive, and J. Zweimüller (2009). Does Culture Affect Unemployment? Evidence from the Röstigraben. IZA Discussion Paper 4283, Institute for the Study of Labor (IZA), Bonn.

Chamberlain, G. (1980). Analysis of Covariance with Qualitative Data. The Review of Economic Studies 47, 225-238.

Chamberlain, G. (1984). Panel Data. In Z. Griliches and M. Intrilligator (Eds.), Handbook of Econometrics, Volume 2, Amsterdam, pp. 1247-1318. Elsevier.

Clark, A. (2003). Unemployment as a Social Norm: Psychological Evidence from Panel Data. Journal of Labor Economics 21(2), 323-351.

Clark, A., Y. Georgellis, and P. Sanfey (2001). Scarring: The Psychological Impact of Past Unemployment. Economica 68(270), 221-241.

Clark, A., A. Knabe, and S. Rätzel (2009). Unemployment as a Social Norm in Germany. Schmollers Jahrbuch 129(2), 251-260.

Diekmann, A., H. Engelhardt, B. Jann, K. Armingeon, and S. Geissbühler (1999). Der Schweizer Arbeitsmarktsurvey 1998. Working Paper, University of Bern.

Diener, E. and R. Lucas (2000). Subjective Emotional Well-Being. In M. Lewis and J. Haviland (Eds.), Handbook of Emotions, New York, pp. 325-337. Guilford. 2nd edition.

Diener, E. and M. Seligman (2004). Beyond Money: Toward an Economy of Well-Being. Psychological Science in the Public Interest 5, 1-31.

Diener, E. and E. Suh (1999). National Differences in Subjective Well-Being. In D. Kahneman, E. Diener, and N. Schwarz (Eds.), Well-being: The Foundations of Hedonic Psychology, New York, pp. 434-450. Russell Stage Foundation.

Dorn, D., J. A. Fischer, G. Kirchgässner, and A. Sousa-Poza (2007). Is it Culture or Democracy? The Impact of Democracy and Culture on Happiness. Social Indicators Research 82, 505-526.

Dorn, D., J. A. Fischer, G. Kirchgässner, and A. Sousa-Poza (2008). Direct Democracy and Life Satisfaction Revisited: New Evidence for Switzerland. Journal of Happiness Studies 9, 227-255.

Ferrer-i-Carbonell, A. and Frijters, P. (2004). How important is Methodology for the Estimates of the Determinants of Happiness? The Economic Journal 114, 641-659.

Frey, B. and A. Stutzer (2002a). Happiness and Economics: How the Economy and Institutions Affect Human Well-Being. Princeton: Princeton University Press.

Frey, B. and A. Stutzer (2002b). What can Economists learn from Happiness Research? Journal of Economic Literature 40, 402-435.

Graham, C. (2008). The Economics of Happiness. In S. Durlauf and L. Blume (Eds.), The New Palgrave Dictionary of Economics. Palgrave Macmillan. 2nd edition.

Guiso, L., P. Sapienza, and L. Zingales (2006, Spring). Does Culture affect Economic Outcomes? Journal of Economic Perspectives 20(2), 23-48. 
Hofstede, G. (1984). Culture's Consequences. International Differences in Work-Related Values (Abridged ed.). London and Beverly Hills: Sage Publications.

Kassenboehmer, S. and J. Haisken-DeNew (2009). You're Fired! The Causal Negative Effect of Unemployment on Life Satisfaction. The Economic Journal 119, 448-462.

King, G., C. Murray, J. Salomon, and A. Tandon (2004). Enhancing the Validity and CrossCultural Comparability of Measurement in Survey Research. American Political Science Review 98, 191-207.

Knabe, A., S. Rätzel, R. Schöb, and J. Weimann (2010). Dissatisfied with Life but Having a Good Day: Time-Use and Well-Being of the Unemployed. The Economic Journal 120, 867-889.

Lazear, E. P. (1999). Culture and Language. The Journal of Political Economy 107(S6), S95-S126.

Mayer, K. (1951). Cultural Pluralism and Linguistic Equilibrium in Switzerland. American Sociological Review 16(2), 157-163.

McRae, K. D. (1998). Conflict and compromise in multilingual societies: Switzerland (2 ed.). Ontario, Canada: Wilfrid Laurier University Press.

Oswald, A. (2006). The Hippies were right all along about Happiness. Financial Times.

Oswald, A., E. Proto, and D. Sgroi (2009). Happiness and Productivity. IZA Discussion Paper 4645, Institute for the Study of Labor (IZA), Bonn.

Senik, C. (2011). The French Unhappiness Puzzle: the Cultural Dimension of Happiness. Working Paper 2011-34, Paris School of Economics.

Stutzer, A. and R. Lalive (2004). The Role of Social Work Norms in Job Searching and Subjective Well-Being. Journal of the European Economic Association 2(4), 696-719.

Tabellini, G. (2010). Culture and Institutions: Economic Development in the Regions of Europe. Journal of the European Economic Association 8(4), 677-716.

Triandis, H. (2000). Cultural Syndromes and Subjective Well-Being. In E. Diener and M. Suh (Eds.), Culture and Subjective Well-Being, Cambridge, MA, pp. 13-36. MIT Press.

Veenhoven, R. (2008). Healthy Happiness: Effects of Happiness on Physical Health and the Consequences for Preventive Health Care. Journal of Happiness Studies 9, 449-469.

Winkelmann, L. and R. Winkelmann (1998). Why are the Unemployed So Unhappy? Evidence from Panel Data. Economica 65, 1-15. 


\section{Tables}

Table 1: Average Life Satisfaction by Employment Status and Language

\begin{tabular}{lccc}
\hline & Swiss German & Swiss French & Swiss Italian \\
\hline All & 8.037 & 7.822 & 7.954 \\
& $(1.232)$ & $(1.392)$ & $(1.220)$ \\
Employed & 8.045 & 7.850 & 7.956 \\
& $(1.225)$ & $(1.359)$ & $(1.222)$ \\
Unemployed & 7.161 & 6.529 & 7.500 \\
& $(1.680)$ & $(2.119)$ & $(0.707)$ \\
\hline \# Observations & 12,226 & 4,034 & 679 \\
\hline
\end{tabular}

Source: SHP, own calculations. Standard deviations in parentheses.

Table 2: Average Life Satisfaction among Migrants in Switzerland

\begin{tabular}{lccc}
\hline & German & French & Italian \\
\hline All & 7.869 & 7.454 & 7.700 \\
& $(1.129)$ & $(1.635)$ & $(1.439)$ \\
\hline \# Observations & 375 & 218 & 707 \\
\hline
\end{tabular}

Source: SHP, own calculations. Standard deviations in parentheses.

Table 3: Opinion on Social Expenses

\begin{tabular}{lccc}
\hline & Swiss German & Swiss French & t-test \\
\hline All & 2.039 & 2.421 & $* * *$ \\
Unemployed & $(0.737)$ & $(0.738)$ & $* *$ \\
\multirow{2}{*}{ Employed } & 2.162 & 2.442 & $* 0.752)$ \\
& $(0.817)$ & 2.420 & $* * *$ \\
\hline \# Observations & 2.038 & $(0.738)$ & \\
\hline
\end{tabular}

Source: SHP, own calculations.

Note: Standard deviations in parentheses. *** significant at 1\%; ** significant at 5\%; * significant at $10 \%$. Lowest value 1 refers to being in favor of a diminution and highest value 3 refers to being in favor of an increase of the Confederation social expenses. 
Table 4: Descriptive Statistics

\begin{tabular}{|c|c|c|c|}
\hline & Swiss German & Swiss French & t-test \\
\hline \multirow[t]{2}{*}{ Unemployed } & 0.009 & 0.021 & $* * *$ \\
\hline & $(0.095)$ & $(0.144)$ & \\
\hline \multirow[t]{2}{*}{ Employed } & 0.991 & 0.979 & $* * *$ \\
\hline & $(0.095)$ & $(0.144)$ & \\
\hline \multirow[t]{2}{*}{ Life Satisfaction - All } & 8.039 & 7.822 & $* * *$ \\
\hline & $(1.229)$ & $(1.392)$ & \\
\hline \multirow[t]{2}{*}{ Life Satisfaction - Unemployed } & 7.161 & 6.529 & $* *$ \\
\hline & $(1.680)$ & $(2.119)$ & \\
\hline \multirow[t]{2}{*}{ Life Satisfaction - Employed } & 8.045 & 7.850 & $* * *$ \\
\hline & $(1.225)$ & $(1.359)$ & \\
\hline \multirow[t]{2}{*}{ Age } & 43.883 & 42.183 & $* * *$ \\
\hline & (11.095) & (10.618) & \\
\hline \multirow[t]{2}{*}{ Married } & 0.640 & 0.686 & $* * *$ \\
\hline & $(0.480)$ & $(0.464)$ & \\
\hline \multirow[t]{2}{*}{ Separated/Divorced } & 0.081 & 0.085 & - \\
\hline & $(0.272)$ & $(0.278)$ & \\
\hline \multirow[t]{2}{*}{ Widowed } & 0.010 & 0.004 & $* * *$ \\
\hline & $(0.099)$ & $(0.061)$ & \\
\hline \multirow{2}{*}{ No educational degree } & 0.004 & 0.000 & $* * *$ \\
\hline & $(0.063)$ & $(0.016)$ & \\
\hline \multirow{2}{*}{ Low educational degree } & 0.409 & 0.392 & * \\
\hline & $(0.492)$ & $(0.488)$ & \\
\hline \multirow[t]{2}{*}{ Intermediate educational degree } & 0.416 & 0.369 & $* * *$ \\
\hline & $(0.493)$ & $(0.483)$ & \\
\hline \multirow[t]{2}{*}{ High educational degree } & 0.172 & 0.239 & $* * *$ \\
\hline & $(0.377)$ & $(0.426)$ & \\
\hline \multirow[t]{2}{*}{ Net household income } & $1.25 \mathrm{e}+05$ & $1.19 \mathrm{e}+05$ & $* * *$ \\
\hline & (93097.711) & $(70353.694)$ & \\
\hline \multirow[t]{2}{*}{ Cantonal unemployment rate } & 2.580 & 4.051 & $* * *$ \\
\hline & $(0.008)$ & $(0.022)$ & \\
\hline \# Observations & 12,192 & 4,033 & \\
\hline
\end{tabular}

Source: SHP, own calculations. Cantonal unemployment rate from SECO (State Secretariat for Economic Affairs/Switzerland).

Note: Standard deviations in parentheses. *** significant at $1 \%$; ** significant at $5 \%$; * significant at $10 \%$. 
Table 5: Average Change in Life Satisfaction by Employment Status and Language

\begin{tabular}{lccc}
\hline & Swiss German & Swiss French & t-test \\
\hline Employed in t-1 and unemployed in t & -0.643 & -0.391 & - \\
\# Observations & 56 & 46 & - \\
\hline Unemployed in t-1 and employed in t & 0.464 & 0.267 & - \\
\# Observations & 56 & 45 & -0.051 \\
\hline Employed in t-1 and employed in t & -0.039 & 3,050 & - \\
\# Observations & 9,441 & 0.429 & 14 \\
\hline Unemployed in t-1 and unemployed in t & -0.250 & 12 & \\
\hline
\end{tabular}

Source: SHP, own calculations.

Note: *** significant at $1 \% ; * *$ significant at $5 \% ; *$ significant at $10 \%$. 
Table 6: Step-by-Step Baseline Regression Switzerland

\begin{tabular}{|c|c|c|c|c|c|c|}
\hline & Pooled & Fixed Effects & BUC & Pooled & Fixed Effects & BUC \\
\hline Unemployed & $\begin{array}{l}-1.062 \\
(0.172)^{* * *}\end{array}$ & $\begin{array}{l}-0.501 \\
(0.103)^{* * *}\end{array}$ & $\begin{array}{l}-0.937 \\
(0.184)^{* * *}\end{array}$ & $\begin{array}{l}-1.320 \\
(0.314)^{* * *}\end{array}$ & $\begin{array}{l}-0.446 \\
(0.144)^{* * *}\end{array}$ & $\begin{array}{c}-0.726 \\
(0.249)^{* * *}\end{array}$ \\
\hline Swiss German & $\begin{array}{c}0.205 \\
(0.046)^{* * *}\end{array}$ & - & - & $\begin{array}{c}0.197 \\
(0.046)^{* * *}\end{array}$ & - & - \\
\hline $\begin{array}{l}\text { Unemployed* } \\
\text { Swiss German }\end{array}$ & & & & $\begin{array}{c}0.453 \\
(0.356)\end{array}$ & $\begin{array}{l}-0.095 \\
(0.205)\end{array}$ & $\begin{array}{l}-0.399 \\
(0.365)\end{array}$ \\
\hline \# Observations & 16,225 & 16,225 & 25,250 & 16,225 & 16,225 & 25,250 \\
\hline R Squared & 0.014 & 0.003 & & 0.014 & 0.003 & \\
\hline Log Pseudo-Likelihood & & & $-9,358.019$ & & & $-9,356.943$ \\
\hline
\end{tabular}

Source: Swiss Household Panel (SHP), own calculations.

Note: $* * *$ significant at $1 \%$; ** significant at $5 \%$; significant at $10 \%$. Dependent variable: life satisfaction. Standard errors clustered at the individual level in parentheses. The reference group for employment status is being employed.

Table 7: Step-by-Step Baseline Regression Switzerland - Continued

\begin{tabular}{|c|c|c|c|c|c|c|}
\hline & Pooled & Fixed Effects & BUC & Pooled & Fixed Effects & BUC \\
\hline Unemployed & $\begin{array}{c}-1.288 \\
(0.310)^{* * *}\end{array}$ & $\begin{array}{c}-0.429 \\
(0.142)^{* * *}\end{array}$ & $\begin{array}{c}-0.695 \\
(0.261)^{* * *}\end{array}$ & $\begin{array}{l}-1.149 \\
(0.274)^{* * *}\end{array}$ & $\begin{array}{c}-0.423 \\
(0.143)^{* * *}\end{array}$ & $\begin{array}{c}-0.698 \\
(0.263)^{* * *}\end{array}$ \\
\hline Swiss German & $\begin{array}{c}0.171 \\
(0.085)^{* *}\end{array}$ & - & - & $\begin{array}{c}0.165 \\
(0.085)^{*}\end{array}$ & - & - \\
\hline $\begin{array}{l}\text { Unemployed* } \\
\text { Swiss German }\end{array}$ & $\begin{array}{c}0.435 \\
(0.353)\end{array}$ & $\begin{array}{l}-0.105 \\
(0.204)\end{array}$ & $\begin{array}{l}-0.390 \\
(0.382)\end{array}$ & $\begin{array}{c}0.410 \\
(0.329)\end{array}$ & $\begin{array}{l}-0.103 \\
(0.204)\end{array}$ & $\begin{array}{l}-0.361 \\
(0.384)\end{array}$ \\
\hline Unemployment rate & $\begin{array}{c}-0.060 \\
(0.017)^{* * *}\end{array}$ & $\begin{array}{c}-0.112 \\
(0.016)^{* * *}\end{array}$ & $\begin{array}{c}-0.256 \\
(0.043)^{* * *}\end{array}$ & $\begin{array}{l}-0.081 \\
(0.018)^{* * *}\end{array}$ & $\begin{array}{l}-0.036 \\
(0.033)\end{array}$ & $\begin{array}{l}-0.024 \\
(0.087)\end{array}$ \\
\hline Age & & & & $\begin{array}{l}-0.064 \\
(0.012)^{* * *}\end{array}$ & $\begin{array}{c}-0.084 \\
(0.018)^{* * *}\end{array}$ & $\begin{array}{c}-0.219 \\
(0.047)^{* * *}\end{array}$ \\
\hline Age Squared & & & & $\begin{array}{c}0.0007 \\
(0.0001)^{* * *}\end{array}$ & $\begin{array}{c}0.0007 \\
(0.0002)^{* * *}\end{array}$ & $\begin{array}{c}0.002 \\
(0.0005)^{* * *}\end{array}$ \\
\hline Married & & & & $\begin{array}{c}0.226 \\
(0.051)^{* * *}\end{array}$ & $\begin{array}{c}0.122 \\
(0.068)^{*}\end{array}$ & $\begin{array}{c}0.286 \\
(0.179)\end{array}$ \\
\hline Separated/Divorced & & & & $\begin{array}{l}-0.266 \\
(0.092)^{* * *}\end{array}$ & $\begin{array}{l}-0.244 \\
(0.127)^{*}\end{array}$ & $\begin{array}{l}-0.307 \\
(0.281)\end{array}$ \\
\hline Widowed & & & & $\begin{array}{c}0.169 \\
(0.191)\end{array}$ & $\begin{array}{c}-0.730 \\
(0.266)^{* * *}\end{array}$ & $\begin{array}{l}-1.804 \\
(0.898)^{* *}\end{array}$ \\
\hline No educaction & & & & $\begin{array}{l}-0.067 \\
(0.283)\end{array}$ & $\begin{array}{c}-0.498 \\
(0.42)\end{array}$ & $\begin{array}{l}-0.967 \\
(0.678)\end{array}$ \\
\hline Intermediate educaction & & & & $\begin{array}{c}0.029 \\
(0.041)\end{array}$ & $\begin{array}{c}0.211 \\
(0.085)^{* *}\end{array}$ & $\begin{array}{c}0.439 \\
(0.215)^{* *}\end{array}$ \\
\hline High educaction & & & & $\begin{array}{c}0.003 \\
(0.053)\end{array}$ & $\begin{array}{c}0.268 \\
(0.109)^{* *}\end{array}$ & $\begin{array}{c}0.638 \\
(0.287)^{* *}\end{array}$ \\
\hline Net household income & & & & $\begin{array}{c}0.351 \\
(0.039)^{* * *}\end{array}$ & $\begin{array}{c}0.116 \\
(0.032)^{* * *}\end{array}$ & $\begin{array}{c}0.213 \\
(0.082)^{* * *}\end{array}$ \\
\hline \# Observations & 16,225 & 16,225 & 25,250 & 16,225 & 16,225 & 25,250 \\
\hline R Squared & 0.021 & 0.012 & & 0.061 & 0.020 & \\
\hline Log Pseudo-Likelihood & & & $-9,247.968$ & & & $-9,183.025$ \\
\hline
\end{tabular}

Source: Swiss Household Panel (SHP), own calculations.

Note: $* * *$ significant at $1 \%$; ** significant at $5 \% ; *$ significant at $10 \%$. Dependent variable: life satisfaction. Standard errors clustered at the individual level in parentheses. The reference group for employment status is being employed, for marital status being single and for educational attainment having a low educational degree. Additional control variables are year and canton dummies. Net household income is included as logarithm of income. 
Table 8: Baseline Regression Switzerland - Generalized Ordered Probit

\begin{tabular}{|c|c|c|c|}
\hline & $\theta_{1}$ & $\theta_{2}$ & $\theta_{3}$ \\
\hline Unemployed & $\begin{array}{c}0.314 \\
(0.783)\end{array}$ & $\begin{array}{l}-0.034 \\
(0.409)\end{array}$ & $\begin{array}{c}-0.670 \\
(0.251)^{* * *}\end{array}$ \\
\hline Swiss German & $\begin{array}{l}-0.840 \\
(0.95)\end{array}$ & $\begin{array}{c}-1.669 \\
(0.587)^{* * *}\end{array}$ & $\begin{array}{l}-0.069 \\
(0.212)\end{array}$ \\
\hline \multirow[t]{2}{*}{$\begin{array}{l}\text { Unemployed* } \\
\text { Swiss German }\end{array}$} & $\begin{array}{c}5.656 \\
(1709.341)\end{array}$ & $\begin{array}{c}0.154 \\
(0.618)\end{array}$ & $\begin{array}{l}-0.454 \\
(0.335)\end{array}$ \\
\hline & $\theta_{4}$ & $\theta_{5}$ & $\theta_{6}$ \\
\hline Unemployed & $\begin{array}{c}-0.715 \\
(0.204)^{* * *}\end{array}$ & $\begin{array}{c}-0.851 \\
(0.194)^{* * *}\end{array}$ & $\begin{array}{c}-0.757 \\
(0.200)^{* * *}\end{array}$ \\
\hline Swiss German & $\begin{array}{c}0.202 \\
(0.149)\end{array}$ & $\begin{array}{c}0.361 \\
(0.130)^{* * *}\end{array}$ & $\begin{array}{c}0.150 \\
(0.109)\end{array}$ \\
\hline \multirow[t]{2}{*}{$\begin{array}{l}\text { Unemployed* } \\
\text { Swiss German }\end{array}$} & $\begin{array}{c}-0.156 \\
(0.277)\end{array}$ & $\begin{array}{l}-0.069 \\
(0.257)\end{array}$ & $\begin{array}{c}0.074 \\
(0.256)\end{array}$ \\
\hline & $\theta_{7}$ & $\theta_{8}$ & \\
\hline Unemployed & $\begin{array}{l}-0.126 \\
(0.244)\end{array}$ & $\begin{array}{c}0.558 \\
(0.273)^{* *}\end{array}$ & \\
\hline Swiss German & $\begin{array}{c}0.257 \\
(0.111)^{* *}\end{array}$ & $\begin{array}{c}0.177 \\
(0.126)\end{array}$ & \\
\hline $\begin{array}{l}\text { Unemployed* } \\
\text { Swiss German }\end{array}$ & $\begin{array}{l}-0.264 \\
(0.307)\end{array}$ & $\begin{array}{c}-0.813 \\
(0.377)^{* *}\end{array}$ & \\
\hline \# Observations & 16,225 & & \\
\hline Log-Likelihood & $-21,529.607$ & & \\
\hline
\end{tabular}

Source: Swiss Household Panel (SHP), own calculations.

Note: $* * *$ significant at $1 \% ; * *$ significant at $5 \%$; significant at $10 \%$. Dependent variable: life satisfaction. Standard errors in parentheses. The reference group for employment status is being employed. Additional control variables are year and canton dummies, cantonal unemployment rate, age, age squared, married, separated/divorced, widowed, educational degrees, and logarithm of net household income.

Table 9: Individuals Living in French-Speaking Region

\begin{tabular}{lcc}
\hline & Pooled & Fixed Effects \\
\hline Unemployed & -1.130 & -0.406 \\
Swiss German & $(0.273)^{* * *}$ & $(0.148)^{* * *}$ \\
Unemployed*Swiss German & 0.363 & $(0.122)^{* * *}$ \\
& -0.689 & -1.602 \\
\hline \# Observations & $(0.831)$ & $(0.737)^{* *}$ \\
R Squared & 4,195 & 4,195 \\
\hline
\end{tabular}

Source: Swiss Household Panel (SHP), own calculations.

Note: *** significant at $1 \%$; ** significant at $5 \%$; * significant at $10 \%$. Dependent variable: life satisfaction. Standard errors clustered at the individual level in parentheses. The reference group for employment status is being employed. Additional control variables are year and canton dummies, cantonal unemployment rate, age, age squared, married, separated/divorced, widowed, educational degrees, and logarithm of net household income. 
Table 10: Bilingual Cantons

\begin{tabular}{lcc}
\hline & Pooled & Fixed Effects \\
\hline Unemployed & 0.008 & -0.157 \\
Swiss German & $(0.553)$ & $(0.284)$ \\
Unemployed*Swiss German & 0.106 & \\
& $(0.102)$ & -0.694 \\
\hline \# Observations & -0.680 & $(0.528)$ \\
R Squared & $(0.667)$ & 3,469 \\
\hline
\end{tabular}

Source: Swiss Household Panel (SHP), own calculations.

Note: *** significant at $1 \%$; ** significant at $5 \%$; * significant at $10 \%$. Dependent variable: life satisfaction. Standard errors clustered at the individual level in parentheses. The reference group for employment status is being employed. Additional control variables are year and canton dummies, cantonal unemployment rate, age, age squared, married, separated/divorced, widowed, educational degrees, and logarithm of net household income.

Table 11: Past Unemployment

\begin{tabular}{lcc}
\hline & Pooled & Fixed Effects \\
\hline Unemployed & -0.912 & -0.486 \\
Swiss German & $(0.165)^{* * *}$ & $(0.113)^{* * *}$ \\
Previously Unemployed & 0.143 & \\
Previously Unemployed*Swiss German & $(0.089)$ & 0.036 \\
& -0.676 & $(0.158)$ \\
\# Observations & $(0.237)^{* * *}$ & -0.037 \\
R Squared & 0.510 & $(0.224)$ \\
\hline
\end{tabular}

Source: Swiss Household Panel (SHP), own calculations.

Note: *** significant at $1 \%$; ** significant at $5 \%$; * significant at $10 \%$. Dependent variable: life satisfaction. Standard errors clustered at the individual level in parentheses. The reference group for employment status is being employed. Additional control variables are year and canton dummies, cantonal unemployment rate, age, age squared, married, separated/divorced, widowed, educational degrees, and logarithm of net household income. 
Table 12: Variable Definitions

\begin{tabular}{|c|c|}
\hline Variable & Definition \\
\hline Swiss German & $\begin{array}{l}1 \text { if first language respondent relates to and masters } \\
\text { best is Swiss-German or German }\end{array}$ \\
\hline Swiss French & $\begin{array}{l}1 \text { if first language respondent relates to and masters } \\
\text { best is French or Swiss-French dialect }\end{array}$ \\
\hline Swiss Italian & $\begin{array}{l}1 \text { if first language respondent relates to and masters } \\
\text { best is dialect from Ticino/Romansh-Italian, Romansh or Italian }\end{array}$ \\
\hline German & 1 if nationality is German \\
\hline French & 1 if nationality is French \\
\hline Italian & 1 if nationality is Italian \\
\hline Opinion on social expenses & $\begin{array}{l}1 \text { if in favor of a diminution of the Confederation social spending; } \\
2 \text { if neither in favor of an increase or decrease; } \\
3 \text { if in favor of an increase }\end{array}$ \\
\hline Unemployed & 1 if unemployed \\
\hline Employed & 1 if employed \\
\hline Life Satisfaction & $0=$ not at all satisfied $\& 10$ completely satisfied \\
\hline Age & Age at interview date \\
\hline Single & 1 if single \\
\hline Married & 1 if married \\
\hline Separated/Divorced & 1 if separated or divorced \\
\hline Widowed & 1 if widowed \\
\hline No educational degree & 1 if incomplete compulsory school \\
\hline Low educational degree & $\begin{array}{l}1 \text { if compulsory school, vocational training, domestic science course, } \\
\text { general training school, apprenticeship }\end{array}$ \\
\hline Intermediate educational degree & $\begin{array}{l}1 \text { if bachelor/ maturity, vocational high school with master certificate, } \\
\text { technical school, vocational high school ETS, HTL etc. }\end{array}$ \\
\hline High educational degree & 1 if university, academic high school, HEP, PH, HES, FH \\
\hline Net household income & Yearly household income, net \\
\hline Cantonal unemployment rate & Cantonal yearly average unemployment rate \\
\hline Swiss German canton & $\begin{array}{l}\text { AG, AI, AR, BE, BS, BL, GL, GR, LU, NW, OW, SG, SH, SO, SZ, TG, UR, } \\
\text { ZG, ZH }\end{array}$ \\
\hline Swiss French canton & FR, GE, JU, NE, VD, VS \\
\hline
\end{tabular}

Source: SHP. Cantonal unemployment rate from SECO (State Secretariat for Economic Affairs/Switzerland). 